\title{
"Poor tax" urged to address mental health issues
}

A "toxic combination of poor social policies and programs, unfair economic arrangements and bad politics" is undermining efforts to treat Canadians with mental health problems and causing even more people to require treatment, mental health experts say.

Canada's failure to address the social determinants of health to the same degree as other developed nations has resulted in a situation in which about $15 \%$ of Canadians now live in "health threatening situations of poverty," Dennis Raphael, a professor of health policy and management at York University in Toronto, Ontario, told delegates to a "Women in Mind" conference held in Ottawa, Ont. on Oct. 21.

Change will require a complete shift in how Canadians think about mental health, as well as earlier interventions to provide support before mental health problems surface, Raphael argued. "Otherwise, we're just dragging people out of the river, but doing nothing to stop them from falling in the first place.'

Such supports might include raising social assistance and disability benefits, or introducing a "poor tax" on wealthier Canadians to help provide basic necessities, such as affordable housing and transportation, to at-risk individuals, he said.

Patient advocate Val DeWitt concurred that Canada must address the social determinants of health, saying that patients are often invisible within the system. "Nobody really listens to us. But we don't have time to wait."

Others argued that systemic needs include improvements in the way in which primary care providers and mental health workers interact. The lack of communication and cooperation between the medical and mental health systems can make the system a "morass" to navigate, said Dr. Elaine Jolly, a professor of obstetrics and gynecology at the University of Ottawa and director of the women's health program at the Ottawa Hospital in Ontario.

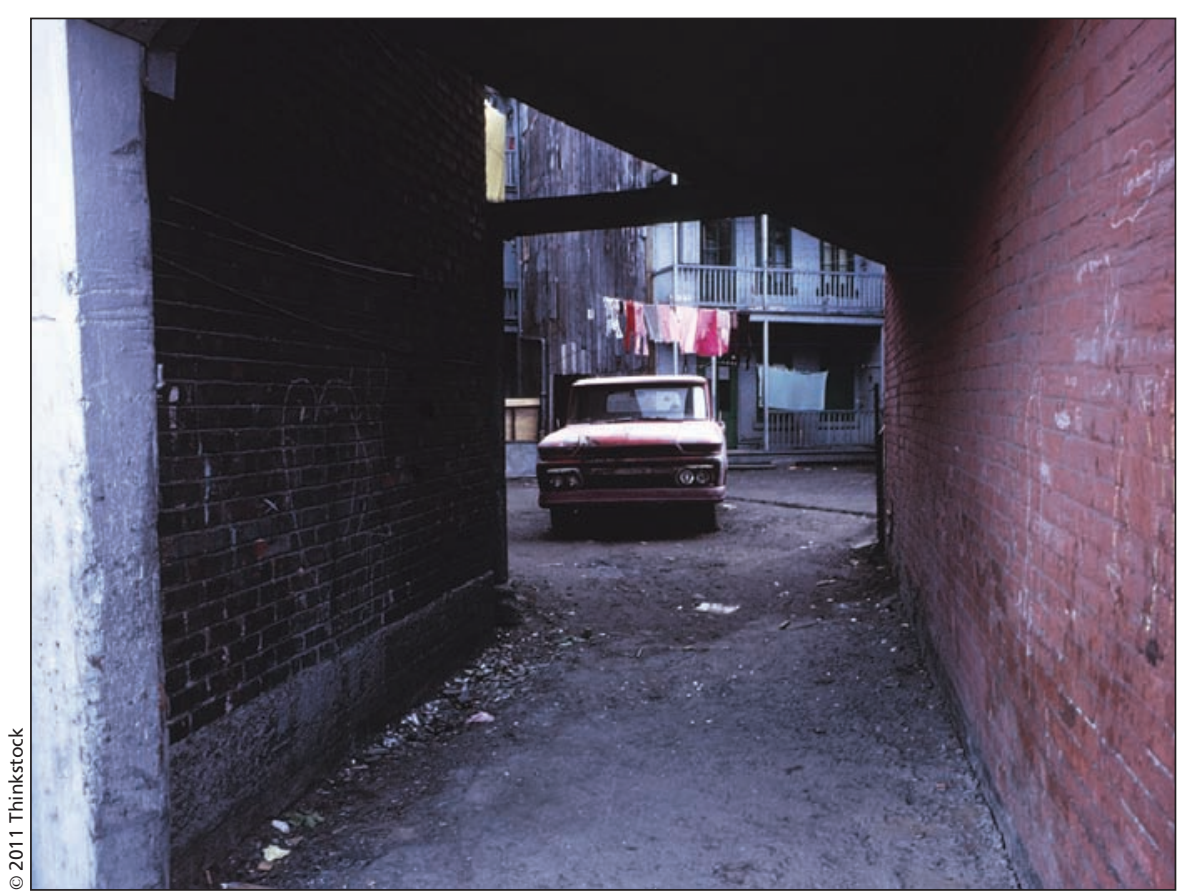

Among measures urged to improve mental health in Canada is the introduction of a "poor tax" on wealthier Canadians to help provide basic necessities, such as affordable housing and transportation, to at-risk individuals.

Delegates to the conference also expressed concerns that the system expects them to "work miracles" in the 15 minutes they typically have to see patients.

Raphael argued that the social determinants of health must be addressed on both a national and a patient level. While governments must ensure that the proper policies are in place to support mental well-being, health care workers must also ensure that poverty, nutrition and other social factors are addressed during treatment.

"If someone's coming in and not eating well, I'd like to think you wouldn't just hand them a pamphlet on healthy eating, but would also inquire if they have a kitchen or enough money to eat."

While the delegates discussed appropriate measures to address the social determinants of health, a United Nations conference on the issue held in Rio de Janeiro, Brazil, on Oct. 21 concluded that "health inequities within and between countries are politically, socially and economically unacceptable, as well as unfair and largely avoidable" (www.who.int/sdhconference/declaration /Rio_political_declaration.pdf).

The nonbinding Rio Declaration on Social Determinants of Health called on governments "to improve daily conditions; to tackle the inequitable distribution of power, money and resources; and to measure and understand the problem and assess the impact of action."

The declaration states that governments need to address "five key action areas" to address social determinants that lead to health inequities, to wit: "(i) to adopt better governance for health and development; (ii) promote participation in policy-making and implementation; (iii) to further reorient the health sector towards reducing health inequities; (iv) to strengthen global governance and collaboration; and (v) to monitor progress and increase accountability."

The pledges aimed at reorienting 
the health sector to reduce inequities included:

"(i) Maintain and develop effective public health policies which address the social, economic, environmental and behavioural determinants of health with a particular focus on reducing health inequities;

(ii) Strengthen health systems towards the provision of equitable universal coverage and promote access to high quality, promotive, preventive, curative and rehabilitative health services throughout the life-cycle, with a particular focus on comprehensive and integrated primary health care;

(iii) Build, strengthen and maintain public health capacity, including capacity for intersectoral action, on social determinants of health;

(iv) Build, strengthen and maintain health financing and risk pooling systems that prevent people from becoming impoverished when they seek medical treatment;

(v) Promote mechanisms for supporting and strengthening community initiatives for health financing and risk pooling systems.

(vi) Promote changes within the health sector, as appropriate, to provide the capacities and tools to act to reduce health inequities including through collaborative action;

(vii) Integrate equity, as a priority within health systems, as well as in the design and delivery of health services and public health programmes; (viii) Reach out and work across and within all levels and sectors of government by promoting mechanisms for dialogue, problem-solving and health impact assessment with an equity focus to identify and promote policies, programmes, practices and legislative measures that may be instrumental for the goal pursued by this Political Declaration and to adapt or reform those harmful to health and health equity;

(ix) Exchange good practices and successful experiences with regard to policies, strategies and measures to further reorient the health sector towards reducing health inequities."

Raphael argued that Canada needs to undertake some manner of national review to identify and overhaul societal structures and policies that threaten mental well-being. "If we're serious about change, we're going to have to change the way society operates."

Mental health policies and programs still focus almost exclusively on detection and treatment of mental illness, "with virtually nothing being said about the means by which mental health can be promoted," he added. - Lauren Vogel, CMAJ

CMAJ 2011. DOI:10.1503/cmaj.109-4035 